AROUEOLOGÍA Y SOCIEDAD

№ 26, 2013: 229-248

ISSN: $0254-8062$

RECIBIDO: 15 / JUL. / 2013

ACEPTADO: $30 / \mathrm{JUL} . / 2013$

\title{
LA MONTAÑA SAGRADA DE SALKANTAY: SU PAISAJE, PODERY ANCESTROS
}

\author{
WILBER BOLÍVAR YAPURA \\ Ministerio de Cultura, Dirección Desconcentrada de Cultura - Cusco \\ wilberbolivar@gmail.com \\ YONY DUEÑAS CASTILLO \\ Ministerio de Cultura, Dirección Desconcentrada de Cultura - Cusco \\ illayony@yahoo.es
}

\section{RESUMEN}

Para los habitantes de los Andes, la reverencia a los apus, montañas sagradas, convertidas en protectores locales, no paso desapercibido en el tiempo, así, las montañas como la del Salkantay, entre otras de las que la rodean asumen un rol importante en la cosmovisión andina. Por ejemplo el nevado del Waqay Willke (5720 $\mathrm{msnm}$ ), dentro de la simbología tradicional del pensamiento dual andino, es considerado el complemento del Salkantay que es una de las deidades más poderosas y activas del lugar, además es apreciado por los habitantes, el padre de todas las montañas de la región y aun en la actualidad es objeto de gran veneración, por lo que Machupicchu y Choquechurco mantienen un íntimo contacto visual con el Salkantay y otros nevados de la cadena del Vilcabamba.

Palabras ClaVE: Montaña, agua sagrada, paisaje, Salkantay, deidad, poderosa, veneración, Vilcabamba.

\begin{abstract}
For the people of the Andes, the Apus reverence and sacred mountains, converted into local protectors, did not go unnoticed at the time, so, as the Salkantay mountains, including the surrounding ones, assume an important role into the Andean worldview. For example the Waqay Willke snowy peak $(5720 \mathrm{~m})$, within the traditional Andean symbolism of dualistic thinking, is considered the complement of Salkantay, that is one of the most powerful and active deities of the place, and it is appreciated by the people, the father of all the mountains in the region and even nowadays is held in great veneration, so Machupicchu and Choquechurco holds an intimate visual contact with the Salkantay and other snowy peaks of the Vilcabamba chain.
\end{abstract}

KEYWORDS: Mountain, sacred water, landscape, Salkantay, deity, powerful, veneration, Vilcabamba 


\section{LA CADENA DEL VilCABAMBA}

La llaqta sagrada y administrativa de Machupicchu está localizada entre importantes nevados de la vertiente oriental de la cordillera de Vilcabamba, «Salkantay, (Humantay Yanantay y Tokorhuay que la rodean) y Waqay Willke» ${ }^{1}$ cuyas montañas, objeto de culto, posibilitan una cohesión social que gira en torno a su veneración, por ser estas proveedoras de agua, elemento vital, principio de existencia en el mundo andino, así como generar fertilidad en los animales, protección a sus pobladores y éxito en las cosechas.

En el culto a las montañas de la zona, están involucrados factores religiosos, políticos y económicos; importantes dentro del proceso de desarrollo social de sus comunidades, los mismos que han estado presentes durante siglos, y que resultan y resultaron muy familiares a los habitantes andinos de todos los tiempos.

La visión actual de los habitantes de la Montaña Sagrada (Mollepata, Machupicchu, Santa Teresa, Wayraqmachay, Collpapampa, Totora, Yanama) vigente desde el tiempo de la sociedad inca, es compartida por pueblos andinos, de tal suerte que la zona es conocida por la reverencia a las montañas sagradas, difícilmente ignoradas y que sin duda juegan una función vital a través del tiempo.

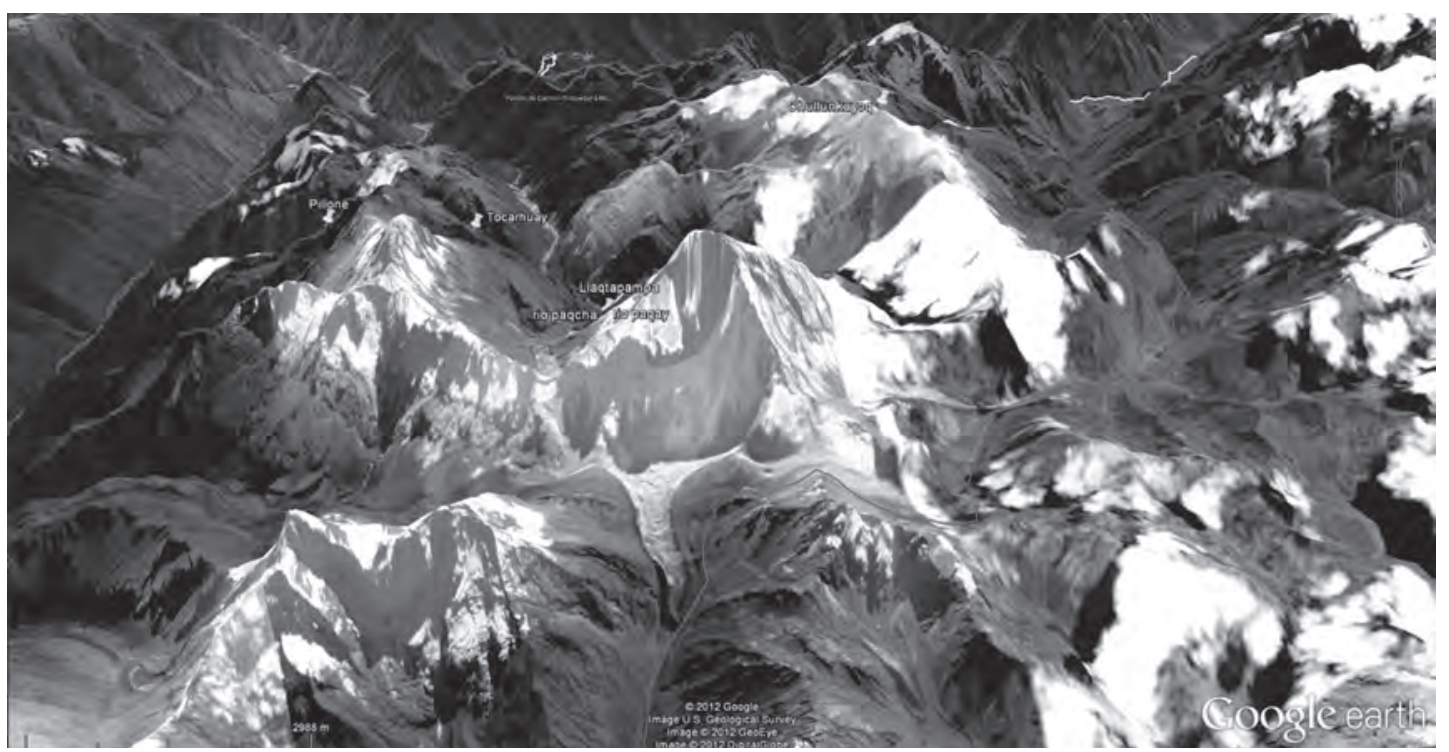

El glaciar del Salkantay con la montaña Salkantay, rodeada de las montañas del Humantay Yanantay y Tokorhuay. (Fuente Google Earth 2012).

1 Estas montañas sagradas están ubicadas dentro del polígono de delimitación del Santuario Histórico de Machipicchu (SHM), declarado como tal mediante decreto supremo № 001-81-AA del 8 de enero de 1981, con una superficie de 32.592 ha. De igual modo en la zona de amortiguamiento (ZA) del SHM precisado mediante resolución jefatural № 322-2001-INRENA del 16 de septiembre del 2004, que propone la ampliación de la ZA a partir de incluir cuencas hidrográficas inmediatas continuas al área del SHM, incrementando el aérea de la ZA de las vigentes en 71.589 ha a 193.334 ha. Finalmente, también está considerado dentro del Parque Arqueológico Nacional de Vilcabamba-Choquequirao, declarado mediante resolución directoral nacional № 949/INC, de fecha 9 de octubre de 2002, que resuelve: «Aprobar el Plano de Delimitación del Parque Arqueológico Nacional de Vilcabamba (Choquequirao), Plano № V-01, de fecha julio del 2002, con un área de 522,878,30 hectáreas y un perímetro de 367,09 kilómetros, a escala 1: 125.000, ubicado en las provincias de La Convención, Anta y Abancay, en los departamentos de Cusco y Apurímac». 


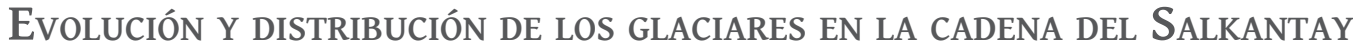

En la época en que las áreas glaciares de la cuenca del Aobamba alcanzaron su máximo desarrollo, los glaciares descendían probablemente hasta la cota de los 2950 m y en la medida en que las condiciones climáticas ambientales fueron cambiando, se inicia un proceso de desglaciación, observándose por una parte que de acuerdo a la morfología preexistente, se desarrolló la corriente glaciar principal a lo largo del cauce del valle del Aobamba, la que durante su retroceso fue subdividiéndose en las zonas de las quebradas afluentes, generándose a su vez en estas últimas, las cuencas glaciares secundarias, tales como en los casos de las quebradas Mesada, Tokorhuay, Paccha Grande, Sisaypampa y Orcospampa, que son las de mayor recorrido en la zona alta de la cuenca principal. Por otra parte, en las laderas de los flancos del valle en que los taludes son de fuerte pendiente, el retroceso glaciar de los frentes se dio en forma casi paralela al eje longitudinal de la corriente glaciar principal.

Actualmente, los glaciares que pertenecen a Aobamba están concentrados alrededor de los cerros Palkay $(5422 \mathrm{~m})$, Salkantay $(6264 \mathrm{~m})$ y Tokorhuay $(5473 \mathrm{~m})$, evidentemente año tras año continúan perdiendo extensión y volumen. En los últimos treinta años el ritmo de fusión glaciar se ha incrementado en forma acelerada, atribuyéndose las causas de dicha fusión a los efectos de invernadero.

\section{GRUPO SALKANTAY}

Salkantay, de 6264 metros de altura, es el nevado más importante de la cordillera Vilcabamba y ocupa la posición sur de la cuenca del valle del Aobamba. De sus laderas nacen las quebradas Sisaypampa, Orcospampa y Paccha Grande.

En 1963 se inventariaron cinco glaciares principales², como pertenecientes a la cuenca del río Aobamba, ubicados en el lado septentrional de la montaña y orientados al noreste y noroeste. De estos, cuatro corresponden al tipo montaña y uno al tipo de valle.

La superficie glaciar total del nevado Salkantay en el ámbito de la cuenca del Aobamba, al año 1963 era de $8.59 \mathrm{Km}^{2}$ y a 1998 según la imagen satelital fue de $3.98 \mathrm{Km}^{2}$, en consecuencia se ha encontrado una reducción de $4.61 \mathrm{Km}^{2}$ de hielo que corresponde a una pérdida del área glaciar del 53,8\% para un periodo de 35 años.

En la actualidad el borde inferior del área glaciar de Salkantay se encuentra a los $\pm 4800 \mathrm{msnm}$, y debido al acelerado proceso de desglaciación, este nivel seguirá ascendiendo en los próximos años.

Desde el punto de vista geodinámico, es en el sector de Salkantay se han generado entre 1996 y 1998 cinco eventos. Tres de los cuatro que se produjeron en la cuenca del río Aobamba y que ocurrieron el 12 de julio de 1996, 12 de marzo y 22 de noviembre de 1998, que fueron originados a partir de la ruptura y desprendimiento de masas glaciares colgantes. El aluvión del 27 de febrero de 1998 que produjo el represamiento del río Vilcanota y afectó la central hidroeléctrica de Machupicchu, se produjo a consecuencia de un proceso de solifluxión que se originó en el talud exterior del arco morrénico frontal que encierra la lengua glaciar, cuyo flujo en el tramo inicial donde se presenta un escalón de roca de aproximadamente $80 \mathrm{~m}$ de desnivel, incrementó su velocidad y capacidad de destrucción.

Muchas partes de la montaña donde se presentan cambios de pendiente en la roca base de tipo granítico y las masas glaciares han tenido poco espesor, estas últimas ya se han ablacionado, quedando cada vez mayores superficies de roca expuesta, por lo cual las corrientes de hielo principales están subdividiéndose y en la medida en que el proceso de desglaciación continúe al ritmo en que se viene produciendo, en los próximos años se infiere que habrán sectores en la zona baja del Salkantay que se presentarán como depósitos de hielo aislados, con tendencia a extinguirse.

2 En: «Estudio Glaciológico de la cuenca del río Aobamba», octubre de 1999 encargado por la Empresa de Generación Eléctrica Machupicchu S.A. (EGEMSA) al Instituto Geológico Minero y Metalúrgico (INGEMET). 
En torno al aspecto de riesgos, la perdida de área glaciar y la ostensible disminución del volumen de hielo no sólo en Salkantay, sino también en el resto de glaciares, se traduce como una situación favorable en el sentido de que las avalanchas y desplomes de las masas de hielo cada vez serán de menor magnitud. De igual modo se ha observado que la zona baja de los glaciares que pertenecen al Salkantay, y de donde se produjeron las avalanchas citadas en líneas anteriores, en la actualidad son de poco espesor y yacen sobre superficies de roca de mediana pendiente; sólo del frente terminal del glaciar № 15 que se ubica en la parte superior izquierda de la laguna Salkantay, se están produciendo continuos desplomes de hielo que caen directamente sobre la masa glaciar en proceso de extinción que va generando la formación y desarrollo de lagunas.

\section{SÍNTESIS HISTÓRICA DEL ÁMBITO DEL PROYECTO}

Las posiciones y enfoques acerca del proceso de ocupación del área de estudio se constituyen desde la época preinka, como una etapa primordial, en que surgieron las primeras sociedades jerarquizadas basados en el culto, la agricultura, ganadería y en nuestro caso en el dominio de los pisos ecológicos, los que estaban organizados desde poblados cercanos, como el de Mollepata, relacionados con culto al apu Salkantay, Este territorio reporta escasa información histórica de su pasado preinka; sin embargo, las investigaciones de Modesto Layme Sotelo se remontan desde los años 945-1006 años d.C. Esta se sustenta a partir de una serie de vestigios arqueológicos que ubicó en lugares como Taramoqo, Chilcapata, Qotomarka, etc. El cronista Garcilaso de la Vega (1609) relata que: «esta zona estuvo habitada por los Rimactampus quienes serian conquistados por el primer inca Manco Capac». ${ }^{3}$

En una relación hecha en 1586 se indicaba que el nombre de Mollepata provenía aún del «tiempo del Inga» y significaba «anden de molles», Mollepata junto a Pampaconga, Patallacta, y Chonta eran pueblos del Inca y del sol, es decir eran criados del Inca. Waldemar Espinoza (1975) contrastando la relación de 1586 con un documento de probanza e información de 1575 indica que la gran mayoría de la población que habitaban las márgenes de los ríos Apurímac y Pachachaca eran mitimaes traídos de la Costa del Perú o de otras zonas yungas andinas (cañarís o chachapoyas) que, en muchos casos habían sido trasladados a estas zonas.

Continuando con la relación de 1586, esta indicaba que los pobladores de Mollepata estaban al mando de un curaca y adoraban al sol y árboles, piedras y que tributaban ají y maíz y que además guardaban ganados de la tierra para las guacas que adoraban, su vestimenta consistía en unas camisetas sin mangas con una manta que se colocaban encima y llevaban el cabello largo. Su alimentación consistía en maíz, ají, papas, quinua, ocas, chochos y el yuyu, la descripción extensa en si da más referencias acerca del ámbito del proyecto:

«asimismo en la zona habían árboles diversos como el aliso, chachacomo, quishuar, y el molle los cuales servían como carbón, leña y para hacer tablas y sillas y para la construcción de las casas, aparte del maíz, ají y las papas se daban frutas llamadas de la tierra como las guayabas, lucmas, granadillas, pepinos y ciruelas, plantas medicinales como la chichera servían para curar las heridas. Las viviendas estaban hechas de adobes que cubrían con maderos y paja, la tierra era accidentada y estaba infestada de leones (pumas), osos, gatos monteses y zorros, así como venados, guanacos y perdices. Mollepata

3 «Volviendo al Inca Manco Capac, decimos que después de haber fundado la ciudad del Cuzco, en las dos parcialidades que atras quedan dichas, mando fundar otros muchos pueblos. Al norte de la ciudad se poblaron veinte pueblos, de cuatro apellidos, que son: Mayu, Zancu, Chinchapucyu, Rimactampu. Los más de estos pueblos están en el hermoso valle de Sacsahuana. donde fue la batalla y prisión de Gonzalo Pizarro. El pueblo más alejado de estos está a siete leguas de la ciudad, y los demás se derraman a una mano y a otra del camino real de Chinchaysuyu»(Garcilaso 1976: 18). 
estaba surcado por dos ríos importantes el caudaloso río Bermejo y el río Blanco, este último que venía "de la puna de las nieves de esta sierra que llaman Salcantay. ${ }^{4}$

En relación a esta cita etnohistórica, que nos ayuda a ver al poblado de Mollepata desde la época Inka, estos vivían básicamente en lugares cálidos como Marcahuasi, Cotomarca, Qonoc o Cachu (actual Bellavista) quienes eran mitimaes, que habían sido asentados por los inkas Topa Ynga Yupangui y Guayna Capac, cronistas como Murua (1590) y Cobo (1653) hablan de un cacique llamado Caruarayco o Carbayayso, quien era curaca de Cotomarca en tiempo de Manco Inga, este al parecer era un cacique cañari que había sido puesto por Guayna Capac.

Ya con la presencia de los españoles en territorios del antiguo Tawantinsuyu, Mollepata es concedida como encomienda, primeramente en 1536 al factor Núñez de Mercado, luego en 1548 el pacificador La Gasca revocaría dicha encomienda a favor del capitán Lope Suazo.

Marcahuasi como heredad o tierra particular sería otorgada por merced real al secretario de La Gasca: Don Pedro López de Cazalla, ${ }^{5}$ en 1569 ya con Francisco de Toledo como virrey del Perú Mollepata era encomienda de doña Francisca Robles, viuda del capitán López de Suazo, en la visita y tasa que hace este virrey en 1570 se indicaba que en este repartimiento, de Mollepata, se hallaron 69 indios tributarios, 9 indios viejos e impedidos que no pagaban tasa 69 muchachos de 17 años abajo, 186 mujeres de todas edades y estado que en total hacían eran 353 personas que pagan de tasa 390 pesos de plata ensayada y marcada.

Justamente es en este periodo que se inicia la reducción o acomodamiento de los indígenas de Mollepata en un pueblo de indios a la usanza occidental el cual es el origen del actual pueblo de Mollepata, este pueblo sería puesto bajo la advocación del patrón Santiago razón por la que se llamaría Santiago de Mollepata, esto hace que la población que estaba asentada desde tiempos del Inka en diversos lugares de la zona sean aglutinados en un solo lugar perdiendo el control de las tierras que antes habían usufructuado, en 1586 la mayor parte de la población indígena había desaparecido, situación que sería aprovechada por diversos españoles que empezaron a acceder a las tierras despojadas a los indígenas asentando en ellas propiedades particulares y haciendas.

En un informe hecho en 1689, el cura de Limatambo Joseph de Mesa Guerrero indicaba que en Mollepata habían 18 haciendas, una estancia y cinco asientos, ello indica que la propiedad de las tierras era usufructuado por propietarios particulares, el único bien que aún quedaba en manos de

4 Descripción de la tierra del Corregimiento de Abancay de que es corregidor Niculoso de Fornee. Declaración de Alonso Vaez y Juan Velásquez, antiguos de la tierra sobre los pueblos de San Sebastián de Pampaconga.

5 Juan de Patallata, Santa Ana de Chonta y Santiago de Oropesa. En: Jiménez de la Espada. Relaciones Geográficas de Indias-Perú. Edición y estudio preliminar de José Urbano Martínez Carreras. Madrid, Gráfico Yagues, 1965. Tomo II, pp. 23-26.

Garcilaso al hablar de Marcahuasi indica lo siguiente: «El año de mil y quinientos y sesenta, viniéndome a España, pase por una heredad de Pedro López de Cazalla, natural de Llerena, vecino del Cuzco, secretario que fue del Presidente Gasca, la cual se dice Marcahuasi, nueve leguas de la ciudad, y fue a veintiuno de enero, donde halle un capataz portugués, llamado Alfonso Vaez, que sabía mucho de agricultura y era muy buen hombre. El cual me paseo por toda la heredad, que estaba cargada de muy hermosas uvas, sin darme un gajo de ellas, que fuera gran regalo para un huésped caminante y tan amigo como yo lo era suyo y de ellas; mas no lo hizo; $y$ viendo que yo habría notado su cortedad, me dijo que le perdonase, que su señor le había mandado que no tocase ni un grano de las uvas, porque quería hacer vino de ellas, aunque fuese pisándolas en una artesa, como se hizo (según me lo dijo después en España un condiscípulo mío, porque no había lagar ni los demás adherentes, y vio la artesa en que se pisaron), porque quería Pedro López de Cazalla ganar la joya que los Reyes Católicos y el Emperador Carlos Quinto había mandado se diese de su real hacienda al primero que en cualquiera pueblo de españoles sacase fruto nuevo de España, como trigo, cebada, vino y aceite en cierta cantidad.». (Garcilaso: [1609] 1976 Tomo II 136). 
los indígenas era la estancia de Charqueccolca, para esta época la población natural originaria de Mollepata estaba compuesta por solo 44 indios, 47 indias y 29 niños entre varones y mujeres, en esta época ya se notaba una presencia grande de indígenas forasteros, 117 en total, que habían sido traídos de diversas partes para laborar en las haciendas (Villanueva 1980: 213).

Luego de 1689, el hilo del pasado histórico de Mollepata, se pierde hasta inicios de la República, 1834 para ser exactos, fecha en la que el presidente de la república, José Luis de Orbegozo, hace su paso por este pueblo el cual es descrito rodeado de dos cerros llamados Tilca y Molleccasa, para este momento Mollepata era desde 1819 o 1821 el paso obligado por donde discurría el camino que venía de Lima con dirección al Cusco (Blanco White 1974: 117).

La población estaba compuesta por 1500 habitantes de toda edad y sexo que estatal distribuidos en el pueblo y en las 11 haciendas que había en ese entonces. ${ }^{6}$ En 1845 la tesorería fiscal de ese entonces nos sigue indicando la presencia de una serie de propiedades particulares en Mollepata, al igual que en 1689 no hay ayllus aún más ya no existe la estancia que antes usufructuaban los indígenas. Hacia 1869 Efrain George Squier, viajero ingles de fines del siglo XIX describe a Mollepata como una aldea de miserables chozas en una alta repisa de la montaña, con una iglesia campos alrededor de Mollepata estaban desolados y había dificultad para conseguir agua (Squier 1974: 290).

A finales del siglo XIX e inicios del XX Mollepata deja de ser el paso de los viajeros que se dirigían a Lima o al Cusco, el camino nuevamente, como en la colonia, pasa por inmediaciones de las haciendas Marcahuasi y la Estrella, esto al parecer hace que caiga en decadencia, y lo único que mantenía a Mollepata conectada con el resto de la región eran las haciendas, los viajeros, comerciantes y ganaderos que se dirigían a los valles de Santa Ana. Tras la época de la reforma agraria y la disolución de las haciendas que habían subsistido aún desde épocas coloniales tempranas, Mollepata seria visto como un lugar ubicado al fin del mundo. Las noticias etnohistorícas con respecto a Santa Teresa están relacionadas con la presencia inka en la antigua Vilcabamba y Machupichu, la diversidad de sitios arqueológicos que se tiene en esta zona son muestra de ello aunque es poca la información que se tiene sobre este aspecto.

Ya en la colonia, Santa Teresa es considerada parte conformante de la Gobernación de Vilcabamba. En 1595 la corona española implementaría en todo el espacio del sur peruano un proceso de composición y legalización de tenencia de tierra denominada «Primera visita y composición de tierras» el cual fue realizado por el oidor Alonso Maldonado de Torres a partir del cual se originarían las haciendas coloniales. En este proceso surge la hacienda Guadquiña que abarcó en su momento de mayor expansión gran parte del actual distrito de Santa Teresa.

Acerca de la hacienda Guadquiña se tiene referencias orales y escritas que indican que esta fue parte de las propiedades que la orden de la compañía de Jesús usufructuaba en el Cusco, aunque no hay documentación histórica que lo sustente. En 1689 el cura de la doctrina de Quillabamba y Amaybamba indicaba que Guadquiña era un ingenio propiedad de un don Juan de la Torre, este ingenio azucarero estaba ubicado a una distancia de 16 leguas y al cual dicho cura no había llegado ni podía dar razón porque aunque pertenecía al beneficio de Quillabamba no tenía un puente por donde cruzar a él, esto por lo caudaloso del río. (Villanueva 1982: 177). A partir de ello se podría inferir que Guadquiña no tenía una salida fácil hacia la orilla derecha del Vilcamayo en donde estaban asentados las otras haciendas y poblados que estaban en la ruta que unía a esta zona con el Cusco por lo que su única vía de comunicación estaba relacionada con el camino que iba al Salkantay y Soraypampa y por ende a Mollepata.

Algo que es necesario precisar al momento de querer determinar los antecedentes que se tienen con respecto al camino Mollepata-Salkantay. Santa Teresa, es la función que esta vía cumplió en la

6 Las haciendas eran las siguientes: Ccacho, Pacaibamba, Mollebamba, Antabamba, Manco, Titticaca, Santa Lucia, Parobamba, Marcahuailla, La Banca y Marcahuasi. 
época prehispánica, (básicamente en el periodo inka) y los cambios que se dieron en su uso tras su posterior reutilización durante el periodo colonial y republicano en ese entender dividiremos estos antecedentes en dos aspectos:

Entenderlo como nexo de unión del Centro Administrativo de Choquechurco con Machupicchu, Vilcabamba y el Salkantay durante el periodo Inka hasta 1570 fecha en que es capturado y muerto el inka Tupac Amaru I, liquidándose por ende el último reducto inka en Vilcabamba.

Como parte de un nuevo tipo de función relacionado con el pueblo y haciendas de Mollepata y Santa Teresa y con los pueblos coloniales ubicados en Vilcabamba (Pucyura, Yanama, etc.).

\section{PAISAJE CULTURAL}

El patrimonio natural constituido por elementos que la naturaleza ha creado durante miles de años y que está representado por la variedad de formaciones geológicas, fisiográficas que en conjunto son parte de la belleza escénica del ámbito heterogéneo, en el que se desarrollan los diferentes ecosistemas, formaciones vegetales con la diversidad de especies de flora, las que a su vez son hábitat de la variedad de especies de fauna característica de la zona y constituido por todos aquellos elementos y manifestaciones tangibles o intangibles producidas por las sociedades, resultado de un proceso; donde la reproducción de las ideas y del material se constituyen en factores que identifica y diferencia el espacio natural del Salkantay como paisaje cultural, evidenciada en sus diferentes manifestaciones y expresiones culturales desde una dimensión territorial ilustrando la evolución de la sociedad humana y sus asentamientos a lo largo del tiempo, condicionados por las limitaciones y/o oportunidades físicas que presenta su entorno natural y por las sucesivas fuerzas sociales, económicas y culturales.

En relación a esta dimensión territorial del patrimonio cultural, es evidente la existencia de una gran diversidad y complejidad de paisaje cultural, como resultado de un proceso de transformación, uso, y ocupación del espacio natural del apu Salkantay (emplazado entre los distritos de Limatambo, Mollepata, Machupicchu y Choquequirao), espacio importante, que se constituyó probablemente desde el Intermedio Tardío en uno de los primeros y más importantes apus que fue honrado con ofrendas en ceremonias especiales. A decir de Polo de Ondegardo (1575), "era uno de los principales apus en todo el reyno, el más antiguo que tenían los incas al que realizaban ceremonias con honores y sacrificios» (Polo de Ondegardo 1906: 67). Y de acuerdo a investigaciones etnohistóricas y etnológicas tiene valoración sagrada en su condición de «apu que protege su territorio». Por lo mismo, en época colonial se hizo declinar su importancia, debido a la extirpación de idolatrías ${ }^{7}$ que irrumpió con estas prácticas ideológico - ceremonial de creencias y cultos de las región es andinas. No obstante, el culto religioso no fue erradicado completamente, pues actualmente el Salkantay, conserva y persiste en su importancia simbólica religiosa entre las poblaciones contiguas, considerado una de las más importantes montañas en las invocaciones de las ceremonias de agradecimiento hacia el apu.

\section{ENFOQUE ETNOGRÁFICO}

La investigación etnográfica de las manifestaciones culturales practicadas por grupos humanos desde épocas remotas entorno a la montaña del Salkantay, considerado por sus adversarios como el más poderoso a comparación de las montañas circundantes de Chaupiloma, Amparay, Soray, Umantay, Palcay y Chaupimayo, que en la época inka fue venerado y le ofrecieron ofrendas en ceremonias especiales.

7 Proceso de extirpación de las creencias y cultos de las religiones andinas. Este proceso fue documentado en visitas de «extirpación de idolatrías» e indagaciones sobre la religión nativa que constituyen documentos importantes para adentrarnos el mundo ceremonial andino. 
Producción Agrícola: siembra de papa y oca (tarpuypacha). Ilustración de Felipe Guaman Poma de Ayala siglo XVII (1615).

Este sistema se baso en la posibilidad de lograr una producción segura y abundante vinculada a un continuo y complejo ritual dedicado a la tierra, agua y ha la propia montaña; por la necesidad de contar con el líquido elemento hizo que, los inkas y sus antecesores practicaran sacrificios-ofrendas y/o rituales más significativos, constituyéndose el «agua sagrada» el que deshiela de los nevados sagrados emergiendo y alimentando lagunas, puquiales y ríos, en ese recorrido riega campos de pasturas naturales y espacios agrícolas para el consumo de los animales.

Una de las tantas actividades ceremoniales practicadas por los inka y sus antecesores fue la situa como ritual propiciatorio del agua con sacrificios de niños a fin de obtener buena producción agrícola favorable (Guaman Poma 1615). Levillier (1940: 155) señala textualmente: «el sacrificio de niños para sus montañas aseguraba producción agrícola y protección de sus animales». Sin embargo, no dejó de acudirse, de modo complementario a los rituales y

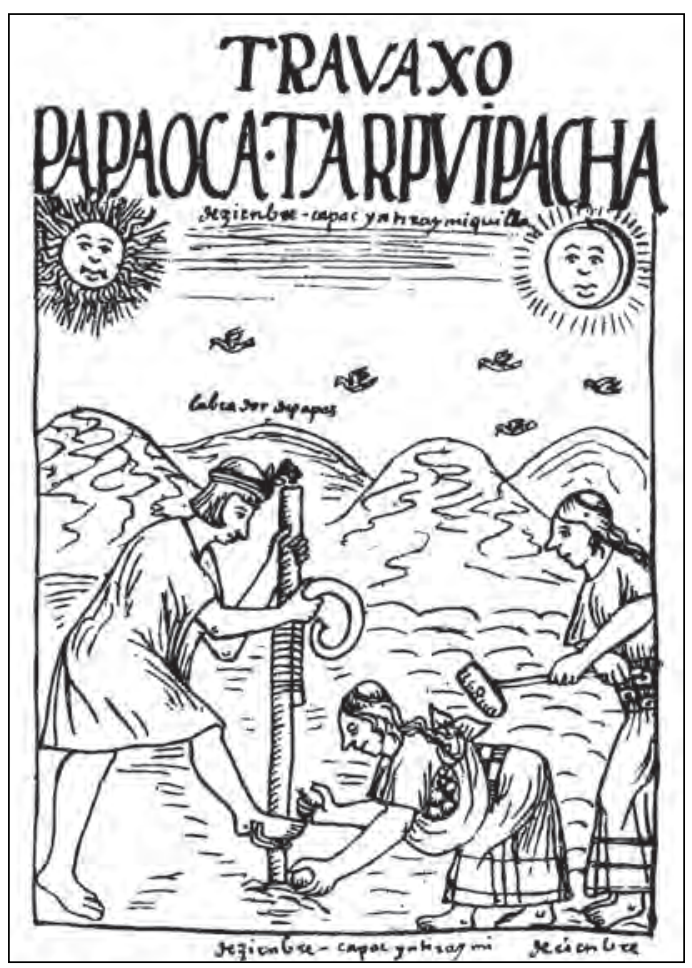
a la magia, para asegurar la productividad y controlar los efectos de inundaciones, sequias y heladas, etc., se habría dado con la intervención humana en términos del manejo tecnológico de «tierra y agua» el desafío a la naturaleza que se dan en dicho territorio.

En este marco, se expresa en el imaginario religioso popular del siglo XVI, el apu Salkantay es catalogado «señor protector» que resguarda a los pueblos de Limatambo, Mollepata, Machupicchu y Choquequirao emplazado en la cordillera del Vilcabamba, manteniéndose «majestuoso y señorial» que, a diferencia del apu Ausangate considerado «el poderoso» en atribución al mito del joven Akanaku y las hijas del apu tenía mucha fortuna en oro, plata y rebaños de llamas, alpacas blancas, vivía acompañado de su esposa «Cayancate» diosa de las alpacas de color, ubicado a un extremo de la laguna de «Singrina qocha» que tiene un color esmeralda, a esta laguna se ofrendada cada 1 de agosto por los pastores de Yanacocha; ellos creen que de los manantes existentes en las zonas salen alpacas que en algunos casos son capturados por los que tienen suerte, pero que en sus manos se convierten en Enqaychus o Illas que son guardados como objetos mágicos dentro del «messa q'epe» (parafernaria pastoril o atado ritual). (Espinoza Martinez 2004).

De a cuerdo a la información etnohistórica, se mantiene la tesis que los alpaqueros y agropastores del territorio lo practican y pervive hoy mediante los paqos y arariwas en la siembra, inflorescencia de la tierra y durante la maduración de los tubérculos, realizando diferentes ofrendas contra el fenómeno natural del granizo y enfermedades a fin de que no afecte sus cultivos y obtengan buena producción que respaldado por mitos y creencias corresponde a épocas ancestrales, cuando guerreros legendarios se convertían en dioses míticos fundadores de pueblos creadores del hombre, de animales, de las plantas y tenían poderes mágicos para transformar y convertirlos en valles fértiles protegidos por los apus que actualmente continúan venerando en pos de la producción y multiplicación de los rebaños.

Testimonios de citadinos Mollepatinos revelan que actualmente se realizan pagos al apu Salkantay, ofreciendo sus ganados a este y a la pachamama, para que no se pierdan ni se enfermen y además sean 
protegidos basándose en la consideración de que «la tierra vive», por lo tanto, tiene un comportamiento animado y puede producir bienes para los campesinos; pero, recíprocamente, también debe ser alimentada por ellos, debe ser «agradecida», de lo contrario no podría dar frutos o, incluso, simbológicamente «agarrar a las personas» (hapisqa) y producirles enfermedades y así para explicar o racionalizar las distintas ofrendas que efectúan a las fuerzas sobrenaturales. Dichas razones refieren a la provisión de alimentos, como acabamos de ver y, como veremos a continuación, a la necesidad de proteger y resguardar el territorio.

Respecto, a los ritos y ofrecimientos en relación con la cría y el cuidado del ganado dentro de la economía familiar es diverso aunque, no muy frecuentemente interviene en la alimentación, y se emplea su fuerza para el trabajo agrícola y para el transporte por su papel en la economía familiar, el poblador mollepatino está interesado en aumentar su ganado y obligado a criarlo y mantenerlo en unas condiciones tales que permitan su máximo aprovechamiento alimenticio o un precio máximo en la venta.

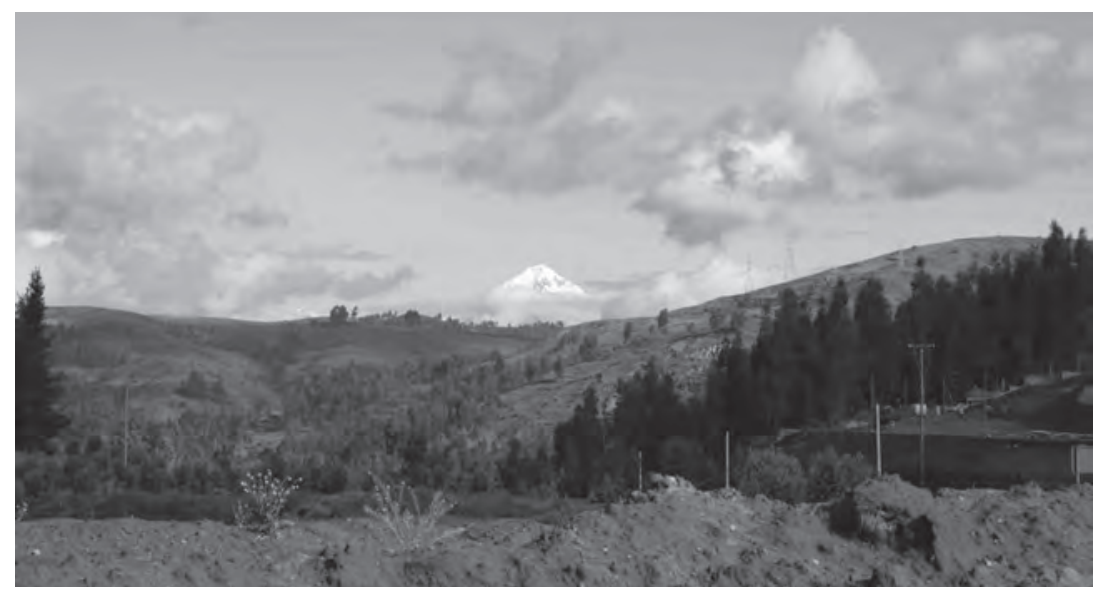

Vista imponente de la montaña del Salkantay desde el Cusco (Arco de Ticatica).

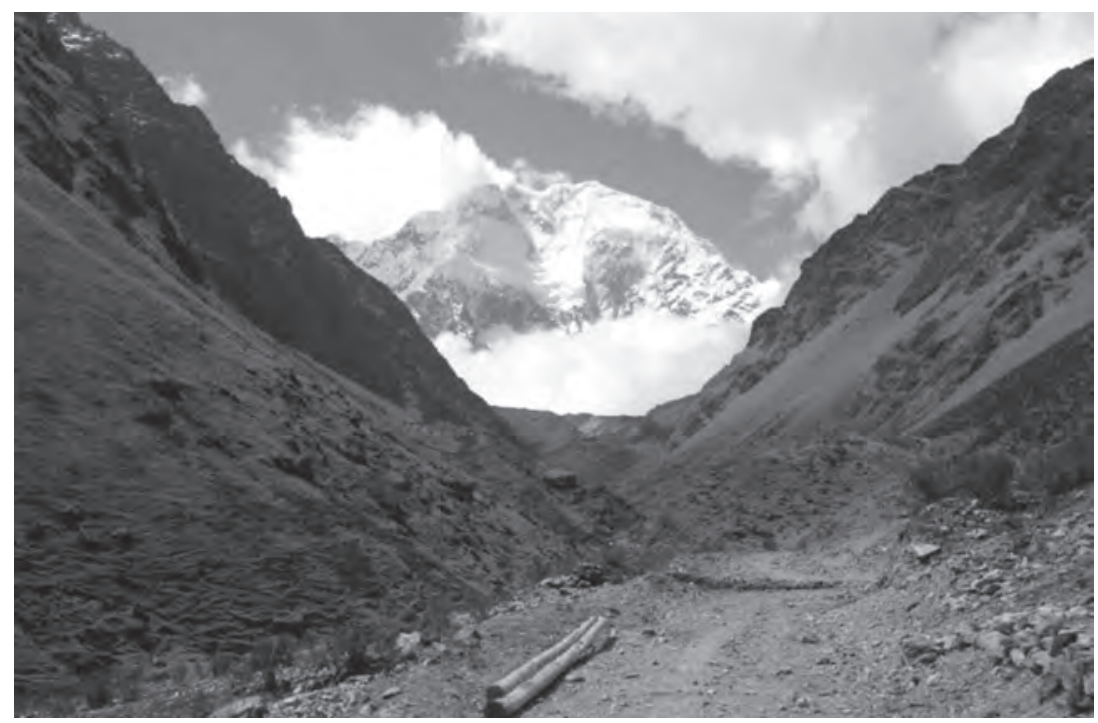

Al fondo la montaña del Salkantay en su macizo desde Soraypampa. 
Con estas finalidades, pues, se llevan a cabo una serie de ritos propiciatorios, para conseguir la mayor fertilidad del ganado, la salud del mismo y para evitar que los animales puedan perderse o ser robados. Para evitar daños de cualquier tipo al ganado y para conseguir una mayor fertilidad existen y se practican una serie de ritos que están relacionados, de una manera específica al ganado ovino desde épocas inmemoriales.

El Salkantay también estaría implicado en los ciclos vitales del río Urubamba, pues las aguas de sus deshielos alcanzan a ambos ríos. Según una hermosa leyenda, «venían las aguas que, fertilizaban a la madre tierra (Pachamama) a través del río Urubamba, que los incas veían desaparecer en la selva amazónica, sin verlo llegar al océano; por lo que creían que sus aguas regresaban durante la noche a sus nevados sagrados desde la selva en forma de un río celestial, que eran las estrellas de la Vía Láctea.

Representa para el andino, el Apu, espíritu, fuerza y energía que rige a toda la naturaleza, en las alturas y cumbre sólidas de los cerros y sus mismas entrañas están poblados de dioses masculinos, desde las cuales se origina el Amaru, el agua que baja hacia las partes profundas de la tierra y a los valles, a las zonas cálidas donde está

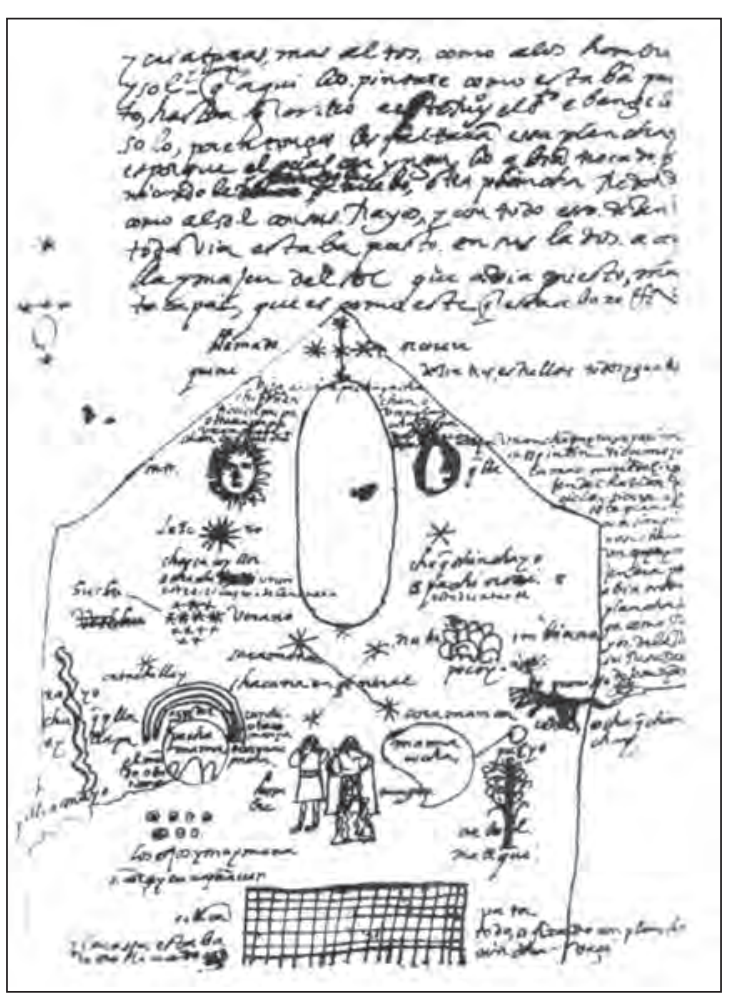

Ilustración. Juan de Santa Cruz Pachacuti, [1613] 1993: 208. Religiosidad inka. la pachamama y la parte liquida se le denomina Mamaqocha, catalogada diosa femenina. Así mismo, concebimos los rayos solares del Tayta inti, el sol. Todos sabemos que por ciencia que no habría vida si no existiera el sol y fundamentalmente el calor de sus rayos solares que con su efecto hace que exista vida y el andino diviniza esas fuerzas naturales, como agradecimiento desarrollando rituales y ceremonias». (Revista Pueblo Indio 8)

En este contexto, estas expresiones religiosas, se plantean con la pretensión de caracterizar algunos de los rasgos esenciales de creencias y mitos del ámbito del Apu Salkantay arraigado a una significancia e ideología religiosa de la sociedad como matriz dualista fundamentada, cuya existencia data desde siglos antes del Estado Inka (Valcárcel 1980: 77). Esta característica, no es exclusiva a razón de que la religión se presenta de un modo homogéneo, así en el caso andino hay una comprobación interesante de tal fenómeno que persiste y que ha llegado hasta nuestros días.

\section{SUBSISTENCIA Y RITUAL AL SALKANTAY}

Atestiguan los diferentes estudios sobre la subsistencia de rituales en el ámbito territorial del Salkantay que, aún se practican y responden a una percepción específicamente andina y cuáles forman parte de un bagaje ideológico-sagrado que fue practicado por nuestros antepasados e impuesto por los conquistadores para legitimar y hacer efectiva su «colonialización» o para ali enar la conciencia sobre la explotación ejercida sobre los indígenas. De cualquier forma, no se nos oculta que la práctica ritual se dio desde épocas remotas que persistió hasta la llegada de los españoles formando un conjunto más o menos sincrético, como los atestiguan los diferentes estudios existentes, sobre la región andina co- 


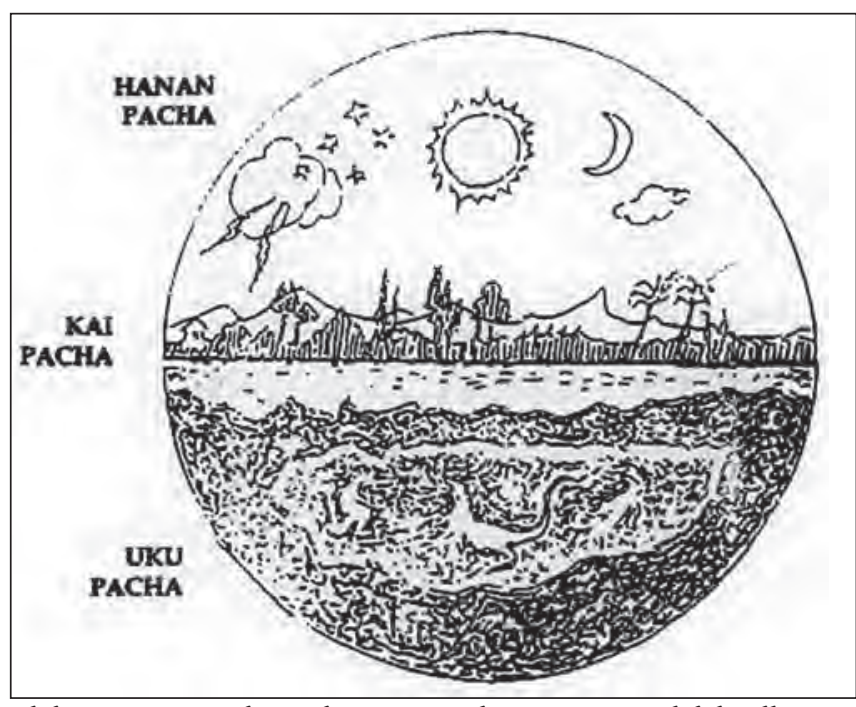

El diagrama trazado predomina por elemento natural del Salkantay dispuesto en el hanan pacha. [En línea] < http://puri-aprendiendovida.blogspot.com/2013/01/uku-pacha-el-mundo-de-abajo.html>

descendientes masculinos y nos han dado su santa bendición». lonializada por los españoles. Metraux (1973, 215 y 225), «de su apego a diversas creencias y prácticas religiosas de los indígenas que se comportan y se dan entre los pobladores de Pampaconga, Limatambo y Mollepata del territorio de Salkantay».

La crónica de Juan Santa Cruz Pachacuti (1968) haciendo referencia a las prácticas religiosas relata «de modo, después de haberse hecho cristianos hijos adoptivos de Jesucristo Nuestro Señor, con acuesta santa fe católica se acabaron haciéndose verdaderos cristianos los indígenas, mostrándose ser enemigos de todas las idolatrías y ritos antiguos, y como tales los persiguieron a los hechiceros, destruyéndoles y derribándoles a todos los guacas y idolos, manifestándolos a los idolatras, castigándoles a sus súbditos y vasallos de toda aquella provincia, y conservaron los susodichos mis antepasados nosotros sus nietos y

Periodo en que el poder eclesiástico español inició un proceso de extirpación de las creencias y cultos andinos documentado en visitas de extirpación de idolatrías e indagaciones sobre la religión indígena que constituyen documentos importantes para adentrarnos al mundo ceremonial andino a través de ritos y tradiciones de Huarochirí (1608) compilado en el texto quechua de autor anónimo que reúne las creencias de los habitantes de la sierra de Lima, cuya compilación fue mandada hacer por Francisco de Ávila, párroco de Huarochirí (1621).

Dichas creencias y cultos se consolidaron con la práctica de ritos y ceremonias a los apus y huacas como lo afirma el padre Arriaga (1621) y relata: «Hallose que en todas partes tenían sus apus comunes de todos pueblos y ayllos, y particulares de cada uno, que les hacían sus fiestas, y ofrecían sacrificios, y tenían todos guardados ofrendas para ellos, los sacerdotes mayores, y menores estaban para los sacrificios, y diversos oficiales para diversos ministerios de sus idolatrías, muchos abusos, supersticiones, $y$ tradiciones de sus antepasados, $y$ lo que causaban más lástima, suma ignorancia de los misterios, y cosas de nuestra fe y todas sus huacas particulares a quien servían los unos y los otros con las ofrendas que tenían para ellas, los vestidos con que hacían las fiestas, los plumajes con que se adornaban, las ollas, cántaros, y vasos de diversas maneras para hacer la chicha, $y$ para beber, $y$ ofrecer a las huacas, las trompetas de ordinario de cobre, $y$ algunas veces de plata, y caracoles muy grandes, $y$ otros instrumentos con que convocaban a las fiestas por los pueblos de Mollepata y sus anexos.» (Arriaga 1916: 12-13).

En referencia a la cita, documentos históricos de 1619 señalan: «[...] en efecto, en el pueblo de Mollepata, por el río Blanco y por él otros pueblos de Pampaconga y Patallaqta existen elementos de la naturaleza como montañas, cerros huacas, quebradas, puquios, cuevas y pozos de agua, del que se dice que todos son elementos que poseen espíritus que habitan en ellos». Vislumbrando una concepción animista de la naturaleza y concepción mágica en los cultos y ceremonias a sus apus, manteniendo una explícita relación con los espíritus de la naturaleza en que los apus y auquis o espíritus de los cerros son llamados también taita (abuelo, padre) quienes pueden proteger o atacar al ganado, y también a las personas previa invocación atribuido al Salcantay apu visible, que se aprecia desde cualquier punto camino del Chinchaysuyo (Contreras 1980). 
Hay todavía otros espíritus que tienen una jurisdicción mayor, con ciertas montañas que han tenido mucho influencia, a las cuales se ha atribuido una acción decisiva en determinados momentos en que se comprometía el interés en interrelación entre el hombre y naturaleza evidenciada en sus diversas manifestaciones, expresiones culturales desde una dimensión territorial en el que resalta la montaña del Salkantay como símbolo cultural- natural, condicionados por las limitaciones y/o oportunidades físicas que presenta su entorno natural y por las sucesivas fuerzas sociales, económicas, religiosas y culturales.

En esta perspectiva, la cosmovisión andina basada en la prehispánica contempla que la naturaleza el hombre y la pachamama (madre tierra), que son un todo y que viven relacionados entre si. Esa totalidad vista en la naturaleza, es para la cultura andina, un ser vivo que tiene un alma, fuerza de vida al igual que lo tienen todas las plantas, animales y montañas, considerando que el hombre se adapta a coexistir con la naturaleza, y por otro lado la cordillera donde se emplazan los nevados, volcanes, montañas, cerros, ríos y lagunas se constituyeron en la época inka sagrados-divinizados por el poblador andino y eran objetos de culto y motivo de celebración de fiestas y rituales especialmente los nevados y montañas fueron lugares sacros donde realizaban ceremonias y cultos religiosos para vivir en armonía con el mundo de arriba (hanan pacha), aqui (kay pacha) mundo de abajo (ukju pacha) relacionado con la pachamama por lo general, de tipo propiciatorio y se realizan en todas aquellas ocasiones en las que está prescrito por la tradición cultural en la medida en que esta expresión es aceptable y permite encontrar comportamientos de los individuos en su medio como expresión e ideología religiosa.

Así el Estado Inka conservó su significancia ideológic-religiosa bajo la representación del cosmos, ordenada en el ukju pacha (mundo de abajo o mundo de los muertos) kay pacha (mundo del presente y de aquí) y hanan pacha (mundo de arriba, celestial o supraterrenal), predominando en esta sucesión y/o categoría el «hanan pacha» en que se hallan las montañas, nevados, cerros al que invoca himnos y a él se dirigen creyentes diciéndoles «tú que no sé si estas en lo alto como ser invisible protege Salcantay a todos los pueblos el cual ha de deberse el triunfo» considerado «señor de todo lo creado». (Valcárcel 1980: 88).

\section{VALORACIÓN CULTURAL DEL TERRITORIO}

\section{HISTORIA Y SIGNIFICANCIA DE LA MONTAÑA Y SU SACRALIDAD}

Cómo símbolo cultural-natural, el Salkantay ubicado al oeste de la ciudad de Cusco a 6271msnm, es representado como «apu tutelar» que rodea y protege a los poblados de Limatambo, Mollepata, Machupicchu y Choquequirao por el camino del Chinchaysuyo y Antisuyo. Sus elevadas cumbres de nieve perpetua le dan la categoría monumental que lo caracteriza como «apu principal concordante a la significancia simbólica y tradición mágica-ideológica al igual que el Ausangate, estas representaron posiblemente desde el Intermedio Tardío «apus poderosos e imponentes con fuerzas mágico espirituales» marcando la valoración e identidad de los pueblos andinos como sus protectores con atribución sacra, el que se enmarca en la cosmogonía andina, rica en su interpretación mágica de los fenómenos y procesos naturales encontrándose entre ellos vínculos con el mundo superior de los dioses o mundo del hanan pacha o «cielo andino».

Es de precisar, que la cosmovisión andina relacionadas con la «adhesión a los apus» parecen haber constituido eventos públicos de gran importancia social y cultural para los inkas quizás y haber ejercido también cierta influencia que excedía el ámbito puramente local en a base de un denominador ideológico común en tiempos en que no había en la zona una estructura política centralizada, considerándose al apu Ausangate como una «deidad» y que todos los pueblos debían peregrinar a rendir culto y en premio se recibía la abundancia en sus ganados y cosecha de sus productos, a diferencia del apu Salkantay rodeado de sus hijos Chaupiloma, Umantay, Padreyoq, Choquetacarpo y Sacsara se le consideraba «dios militar» y que allí peregrinaban los altos mandos del ejercito imperial a recibir instrucciones en técnicas 

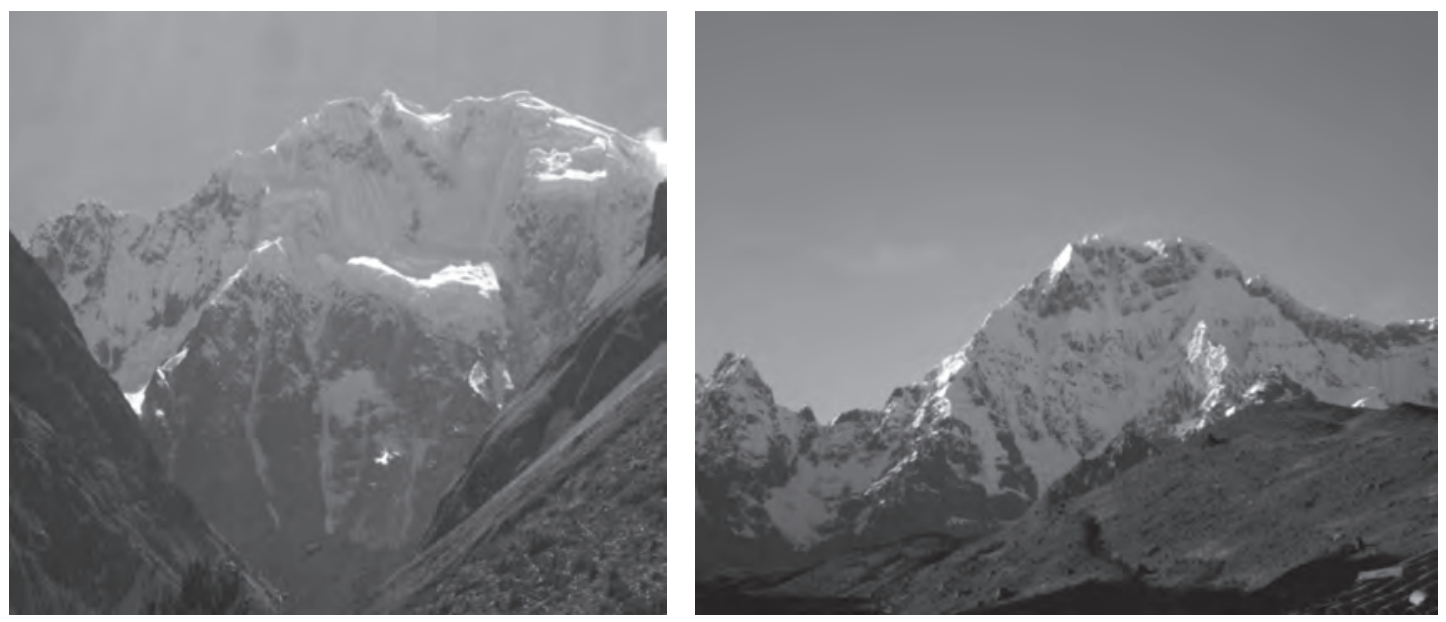

Vistas panorámicas de los apus Salkantay y Ausangate.

y estrategias militares, siendo pocas las evidencias arqueológicas que no permiten aún determinar si existía un marcado control socio - político de estas ceremonias, tal vez a través del auspicio continuado de las mismas por un mismo grupo de descendencia o sector de la comunidad asociados con estas ceremonias, que eran monopolizados por los sacerdotes andinos (Escalante 2011).

En tal consideración, las montañas del Salkantay y Ausangate durante la época inka fueron lugares sacros con poder y/o influencia militar y religiosa. Información del siglo XVI del cronista español Pedro Cieza de León (1962 [1554]: 79) refiere: «camino al Chinchaysuyu poco de cruzar cañón del Apurímac se ven los aposentos de los ingas, y en donde se tenían un oráculo, a lo que los indios dicen por la montaña, junto al cual enterraban oro y hacían sus sacrificios». Siglo después, a mediados del XVII, corroborando el padre Bernabé Cobo (1964:99) en su «Historia del Nuevo Mundo» (libro XII, capítulo IX) relata: «camino a la montaña del Salcantay cruzando el río Apurímac se le rinde honores y célebre de los incas, considerado oráculo por excelencia, hallándose su adoratorio en la cumbre de la montaña donde había gran número de sacerdotes, así como de tierras, rebaños, y poseía un verdadero tesoro por las continuas ofertas de objetos preciosos que recibía el Salcantay a quien ofrecían sacrificios con solemnes ceremonias. Cuando los incas emprendían campañas militares, sobre todo si estas eran guiadas por el Sapa Inca en persona, solían llevar consigo ofrendas a la montaña,
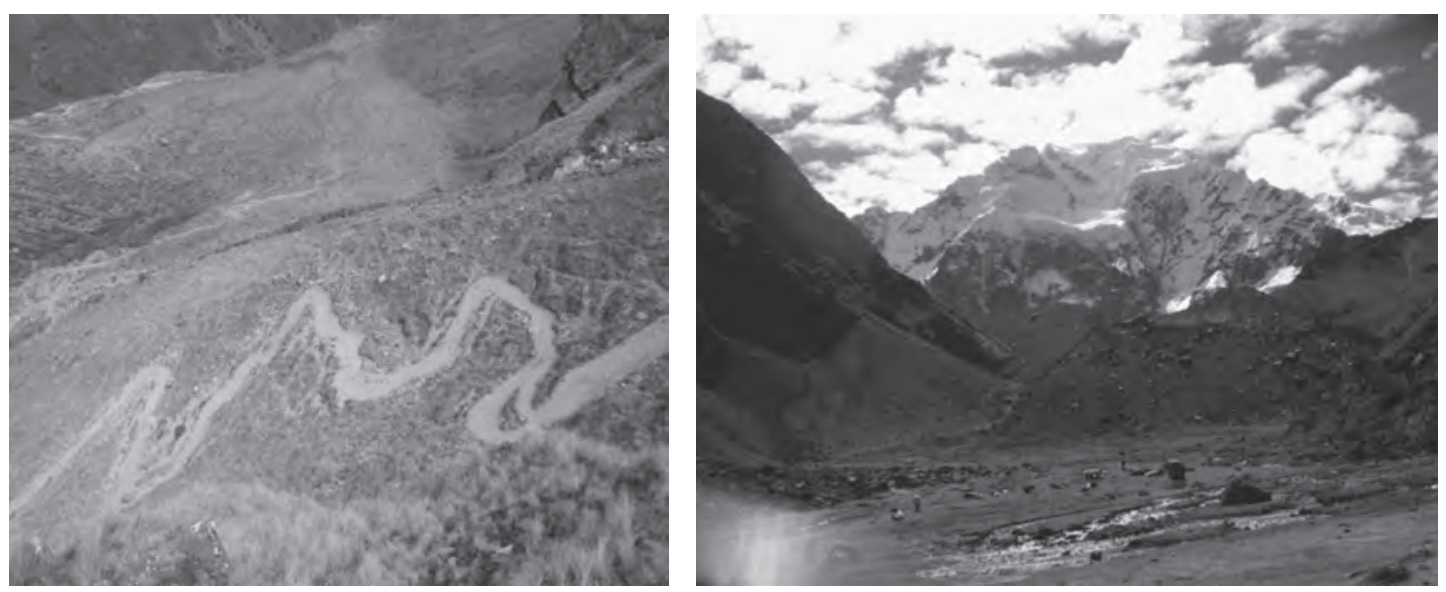

Caminos prehispánicos al Salkantay Sector Huayracpampa. 
a cuyo respaldo atribuian muchas de sus victorias y en sus largas y difíciles jornadas en los confines septentrionales del Imperio, Sinchi Roca y sus sucesores hasta Wiracocha rindieron honores dominando el territorio de la montaña para la preparación de su gente para cualquier enfrentamiento que hubiere y recibirán respuestas favorables».

En este marco, la ideología religiosa inka permanentemente preocupados en buscar la buena voluntad de sus divinidades las que habrían de manifestarse en abundantes frutos y conseguir victorias con la protección de sus dioses locales a donde el sacerdote concurría periódicamente. Luis E. Valcárcel citando a Arriaga (1968 [1621]) señala: «[...] el sumo sacerdote o Willac Uma en un primer periodo era jefe de la iglesia quien reunía en si el poder político, militar y espiritual, a quien encomendó el inka cumplir funciones religiosas especialmente en los altos de las montañas sagradas por mandato del inka era obligado a desprenderse de esas otras funciones para encomendarlas a gente muy vinculada a él por sangre». De modo que la religión y la magia venían a unirse en este poder supremo del sacerdote quien para llegar al desempeño de su oficio era por sucesión «teniendo, la autoridad de realizar sacrificios señalados a las fuentes, manantiales $y$ arroyos que pasaban por los pueblos o cerca de los campos de cultivos y obtener la protección de su apu tutelar para que nos les falte agua en las fuentes y manantiales de los poblados provenientes del Salcantay».

Regal (2009) citando a José de Acosta (1590) expresa: «adoran los incas a los ríos, las fuentes, las quebradas, las peñas o piedras grandes, los cerros, las cumbres, montes que ellos llaman «apachitas» y que están en los caminos encrucijados, en las cumbres para llegar al Salcantay y dejan allí calzados viejos, coca mascada, que es una yerba que muchos usan y, cuando no pueden más, dejan siquiera «una piedra», y todo esto es como ofrenda para que los dejen pasar y le den fuerza», como refiere en documentos del Concilio Provincial de Lima de 1567 citado por Alberto Regal, en cuyo sumario se lee, "Que los adoratorios de los caminos que los indios llaman Apachitas donde procuran estar los sacerdotes a dedicación de sus montañas amontonan piedras uno que otro en poca cantidad y son difíciles de deshacerlos del todo, y en esto se les pone precepto, y si les parece cosa decente pongan una cruz en su lugar.» (Regal 2009).

Dicho sustento religioso enmarca que el apu Salkantay fue, en la época inka lugar sacro que yergue imponente que nace en la cordillera occidental y protege a los pueblos de Limatambo, Mollepata, Machupicchu y Choquequirao y articulado con el camino principal donde se aprecian apachetas que fue practicado desde épocas remotas. Según el cronista Juan de Santa Cruz Pachacuti (1613) «eran piedras amontonadas hechas por los indígenas que están dirigidas a la montaña del Salca antay a quien rendian culto.» ${ }^{8}$ Que, en el siglo XVI, con la evangelización y extirpación de idolatrías muchos de las apachetas fueron destruidos sin embargo, de acuerdo a testimonios orales ${ }^{9}$ actualmente, continúan con la práctica religiosa de alzar apachetas camino al Salkantay. Así, documentos de 1570 a 1620, refieren «las apachetas inka se consideraron sagrados en honor al Salcantay que para llegar al apu tutelar tenían que realizar ceremonias de agradecimiento de deseo de futuro y de buena vida.» ${ }^{10}$

De acuerdo a la información etnohistórica las apachetas habrían tenido su origen en las culturas de habla aymara, posteriormente en la quechua, se han mantenido y dado fuerza en el coloniaje y en la república revelando su existencia en adoraciones rituales de las tradiciones andinas, que hoy en día, podían ser consideradas como «monumentos folklóricos de las antiguas expresiones culturales» y es practicada por los pobladores muchos de ellos manifestando la creencia de dejar las penas, el

8 Juan de Santa Cruz Pachacuti Yamqui Salcamayu contaba que Sinchi Roca Ynga (segundo inca), heredero de Manco Capac, había hecho muchas obras y, entre ellas, había ordenado que cada uno que pasase por determinados lugares en las quebradas debía dejar en esos sitios la piedra que, con ese fin, había cargado desde el valle; también debía dejar el acullico de coca y decir ciertas palabras al cerro (Santa Cruz Pachacuti, 1993[1613]: 200).

9 Definida como el conjunto de creencias y valores morales que rigen la conducta individual y social, como la práctica de rituales que el hombre establece para mantenerse en contacto con lo divino.

10 Archivo Regional de Cusco. Fondo Cabildos de Cusco. Cuadernos 12, 14. Años 1570- 1620. Fol 34, 78. 
cansancio, la desgracia, la mala suerte para que allí se queden sin vuelta alguna, al mismo tiempo masticaban la coca; luego en un breve descanso hacían el nuevo acullico y la "phagua» con el derramado de hojas de coca para llegar al lugar anhelado para que sirva como sitio de mitigación relatora de su pasado.

Al respecto, el padre Cobo (1653) menciona textualmente: «se ofrecía a la apacheta coca mascada, plumas de colores, calzado y piedras en honor al Salcantay así mismo se ofrendaba pedazos de oro y plata o figurillas de los mismos metales que eran enterrados y se ofrecía a dioses y muertos ropa fina, pieza de varón y de mujer, grandes y pequeñas y eran puestos junto a la montaña.» (Cobo; 1964: 133-134). Y los cronistas indígenas del siglo XVII, Juan Santa Cruz Pachacuti (1613) y Phelipe Guamán Poma (1615), coinciden en señalar «... para llegar al Salcantay los incas amontonaban piedras en honor a los cerros, montañas y en los ríos, peñas residían espíritus que invocaban con plegarias y ofrendas a la montaña del Salca antay, a donde se dirigían los incas formando apachitas, o apachejta o montes de piedras, dotados de coca masticada, vestidos con usutas, jirones de ropa u otros elementos que los incas dejaban en expresión de gratitud para los espíritus locales» Corroborando los investigadores de los siglos XIX y XX (Quiroga 1898 en Vignati 1958; Paleari, 1982) señalan «la montaña del Salcantay fue en al época inka una divinidad predominante e influyente del valle del Apurimac».

Estas ofrendas en general aseguran que, eran hechos de la propia hacienda o territorio de cada divinidad y se distingue advirtiendo que no todos los adoratorios mantenían la misma categoría o condición cada uno de ellos era diferente uno del otro, se ofrecía de una misma manera, ni unas mismas cosas ni para los mismos efectos sino que todo estaba bien especificado.

Documentos del Mercurio Peruano de 1794 pone a las apachetas como si fueran divinidades, informa Bollaert «hallándose los «apachitos» en todos los desfiladeros, y tienen probablemente origen inca, en que, los que iban cargados haciendo camino, descansaban sobre ellas en señal de gratitud a las montañas; ofrecían lo primero que le venía a mano del espíritu local que no es hechizo. Relata Murúa (1605): «el ejercicio de la hechicería era considerado como un oficio para gente pobre, razón por la cual los curacas que elegían a los sortilegios escogían aquellas gentes a las cuales faltaban fuerzas para el trabajo colectivo por consiguiente, personas inhábiles que Vivian alejados de los centros poblados y vivían en el retiro de los montes y quebradas». (Murúa 2004: 89).

Se sabe que los curacas en la época inka estaban obligados a conservar las vías cercanas a sus dominios, limpiando la acumulación de tierra en los caminos, el reparado del empedrado y la limpieza de las acequias que protegían los caminos. La apariencia de los caminos al salir de los valles era distinta, puesto que las vías se hacían más anchas y era muy común ver unos apilamientos de piedras que marcaban los puntos escarpados entre los cerros, estos cúmulos eran denominados «apachetas». Como fuera señalado por George Squier entre los años 1863 y 1865, «aquella vieja costumbre de dejar piedras en las cuestas difíciles de los caminos incaicos las convertía con el paso del tiempo en marcas, a manera de hitos, que demarcaban estos caminos». ${ }^{20}$

Con estas referencias y citas, emplazado por la cordillera de Vilcabamba que cubre las cuencas de los ríos Amaybamba, Urubamba, y Apurímac es conocido por dos episodios importantes ocurridos antes y después de la conquista española. Estuvo poblado por diversas etnias Antis, en el periodo inka con Sinchi Roka y su descendencia, tomaron control y dominio del ámbito mandando construir una serie de caminos, recintos, qolqas, y andenes compuesto por una notable uniformidad estructural y aparentemente funcional, pues se está demostrando que los andenes estuvieron destinados al cultivo; ${ }^{11}$ la distinción formalizada del análisis arquitectónico practicado aquí demuestra que la arquitectura, incluso en sus aspectos más simplistas, contiene un cúmulo de información de alto valor inferencial para una arqueología clásica orientada a establecer contextos e interpretaciones articulado a la red vial inka.

11 El estudio palinológico ha documentado este uso: Ver Echevarria y Valencia; 2006. 


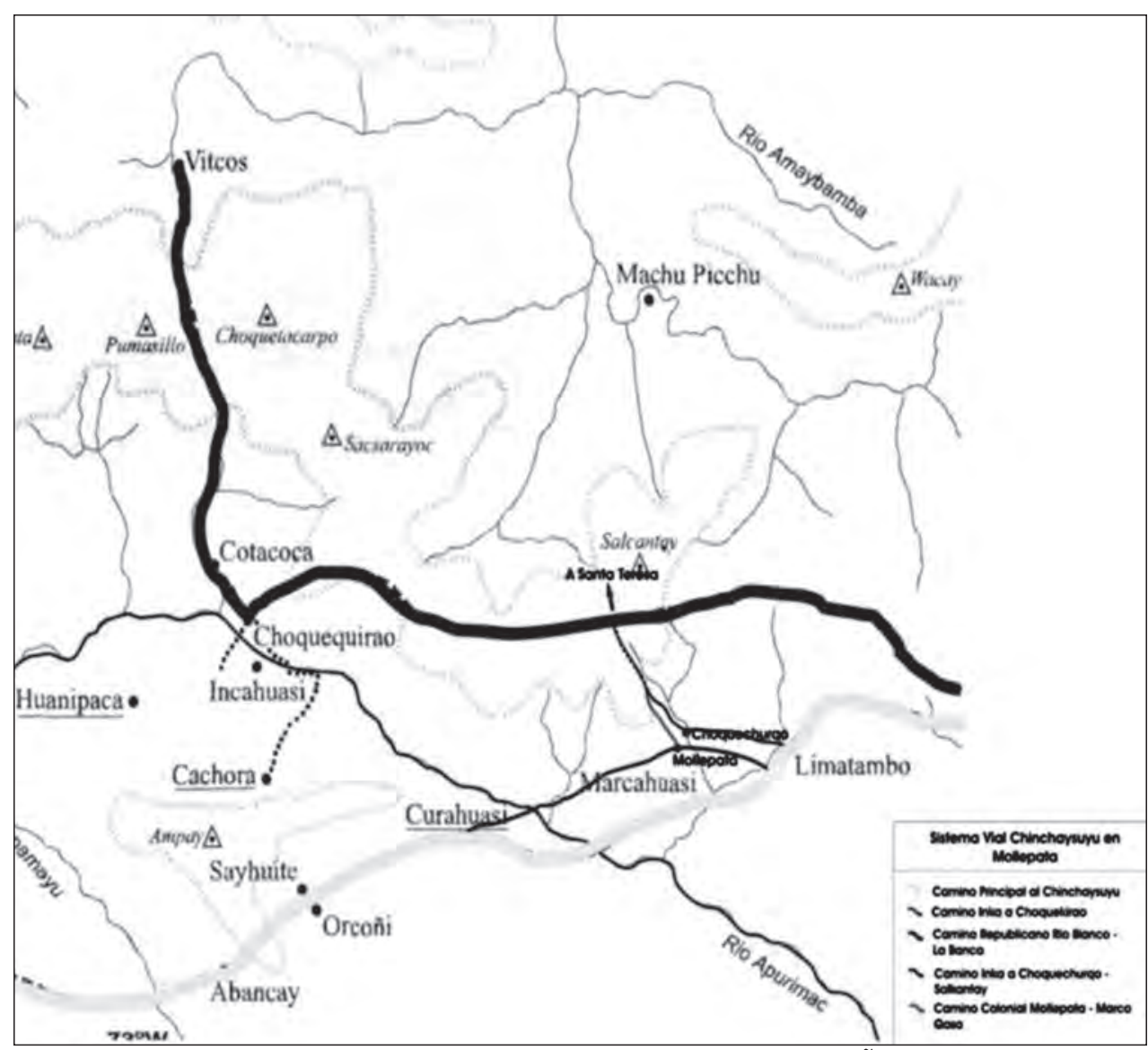

Hacia el Apu Sankantay se hallan tres caminos pre hispánico de Qhapaq Ñan como lo demuestra el plano así, tenemos los caminos inka de Choquechurco, Choquequirao y camino colonial Mollepata Fuente Plano Proyecto Qhapaq Ñan 2007

En este sentido aspectos críticos del contexto arqueológico, «tales como aquellos relacionados a su naturaleza interna, inclusión espacial, secuencia e interrelación con los sitios arqueológicos de Machupicchu y Choquequirao han sido abordados incorporando variables y rasgos materiales y aspectos de localización que, le acercan a una ubicación temprana en la historia imperial del Cusco establecido, como dominio real y/o estatal inka» (Echevarria y Valencia 2006, 2010). Consecuentemente, los estudios arqueológicos realizados desde inicios del siglo XX, focalizaron las problemáticas vinculadas a la dimensión Inka del paisaje, muy a menudo bajo un enfoque histórico determinista a excepción de las investigaciones del Valle de Kusichaca y sus alrededores.

\section{CONSIDERACIONES FINALES}

Salkantay apu montaña sagrada que en complemento con el nevado del Waqay Willke es objeto de veneración junto a Machupicchu, Choquequirao, considerado en el mundo andino «ícono sagrado», posibilitando una cohesión social de veneración desde tiempos inmemorables, confirmando los pobladores su identificación plena con el apu Salkantay; perennizado como una expresión de agradecimiento profundo acorde a sus creencias, rituales y ceremonias de inicio de siembra, cultivo y cosecha de productos agrícolas y de producción pecuaria. 
Mollepata situado en la cadena de Vilcabamba es conocido desde épocas ancestrales como «andes de molles, pueblo del inka y del sol», que en el año 1757 los mitimaes se establecieron en las riberas del Apurímac y Patakancha y próximos a Marcahuasi, Cotomarca, Qonoq Cancha (Bellavita), era encomienda de Francisca Robles viuda del capitán Lorenzo Suaso durante las visitas del virrey Toledo en 1570 quien a la usanza española lo llamo «Santiago de Mollepata» donde se instauraron casas haciendas de Marcahuasi siendo usufructuados al igual que la hacienda la Estrella ubicado en la ruta que unía el camino del Salkantay-Soraypampa. Es este contexto histórico-cultural-natural que Mollepata se constituye patrimonio natural con diversidad y complejidad de paisaje cultural y resultado de un proceso en uso, ocupación y emplazado entre los distritos de Limatambo, Mollepata, Machupicchu y Choquequirao.

Expresado en el imaginario religioso popular del siglo XVI, el apu Salkantay es catalogado como un «señor protector», que resguarda a los pueblos de Limatambo, Mollepata, Machupicchu y Choquequirao emplazados en la cordillera del Vilcabamba, manteniéndose «majestuoso y señorial» al que, a diferencia del apu Ausangate es considerado «el poderoso» en atribución al mito del joven Akanaku y las hijas del apu tenía mucha fortuna en oro, plata y rebaños de llamas, alpacas blancas, vivía acompañado de su esposa «Cayancate» considerada diosa de las alpacas de color, ubicado a un extremo de la laguna de «Singrina qocha» que tiene un color esmeralda, a esta laguna se ofrendada cada $1^{\circ}$ de agosto por los pastores de Yanacocha; creyendo que de los manantes existentes en las zonas salen alpacas que en algunos casos son capturados por los que tienen suerte, pero que en sus manos se convierten en Enqaychus o Illas que son guardados como objetos mágicos dentro del «messa q'epe»(parafernaria pastoril o atado ritual).

A manera de reflexión, el Salkantay nevado importante que ocupa la posición sur de la cuenca del valle del Aobamba, donde se vienen generando eventos de desprendimientos de masas glaciales colgantes, debido al fenómeno del calentamiento global que afecta de manera progresiva la masa glaciar; siendo urgente la conservación y el uso restringido de las áreas protegidas e implementar de políticas de manejo sostenible.

\section{BiBLIOGRAFIA}

\section{ALBERTI, G. y E. MAYER}

1974 Reciprocidad e intercambio en los Andes peruanos. Lima: Instituto de Estudios Peruanos (IEP).

AMADO, Donato

2006 Informe final del sistema vial del Chinchaysuyu. Proyecto Qapaq Ñan, INC.

APARICIO, Manuel

1984 «De Vilcabamba a Camisea. Historiografía de la Provincia de la Convención». Universidad Nacional San Antonio Abad del Cusco (UNSAAC)

ARGUEDAS, José María

1966 [1958] Dioses y hombres de Huarochirí. Narración quechua recogida por Francisco de Ávila (1598?). Lima: IEP. 275 p.

ARRIAGA, Pablo José de

1916 Extirpación de Idolatría en el Perú. Cap. I. Colección de los Libros y documentos referentes a la Historia del Perú.

BAUER, Brian

2000 El espacio sagrado de los Incas. Cusco: Centro Bartolomé de las Casas (CBC).

BLANCO, José María

1974 Diario del viaje del presidente Orbegozo al Sur del Perú. F. Denegri (ed.) Tomo I. Lima: PUCP.

BRUSH, S.B.

1975 «Parentesco y agricultura en un pueblo andino peruano». En: América Indígena XXXV(2): 367-389.

BURCHARD, Roderick

1980 «Exogamia como estrategia de acceso a recursos interzonales: un caso en los Andes Centrales del Perú». En: E. Mayer y R Bolton (eds.), Parentesco y matrimonio en los Andes: 593-616. Lima: PUCP. 
CAMINO, Alejandro

1980 «Tiempo y espacio en la estrategia de subsistencia andina: un caso en las Vertientes orientales sud peruanas». En L. Millones y M. Tomoeda (eds.), El hombre y su ambiente en los Andes Centrales: 11-35. Osaka, Museo Nacional de Etnología.

CASAVERDE, Juvenal

1977 «El trueque en la economía pastoril». En: J. Flores (ed.), Pastores de puna: 117-191. Lima: IEP.

CIEZA DE LEÓN, Pedro

1962 [1554] La Crónica del Perú (primera parte de la crónica del Perú). Madrid: Espasa Calpe.

CISNEROS, Antonio

1993 «Mollepata: Una Historia de las aguas». En: Debate Agrario 17.

COBO, Bernabé

1964 [1653] Historia del Nueva Mundo. Lima: Editorial Atlas.

CONTRERAS, Jesús

1980 «La valoración del trabajo en una comunidad campesina de la sierra peruana». En: Boletín Americanista 30: 41 -68.

DOLLFUS, 0 .

1981 El reto del espacio andino. Lima: IEP.

ECHEVARRÍA, Gori y Zenobio VALENCIA

2006 Investigación Arqueológica del Complejo Arqueológico de Choquequirao Sector VIII Las Llamas. Informe Final 2005 presentado al INC Cusco.

2010 «Las Llamas de Choquequirao, arte imperial cusqueño en roca del siglo XV». Revista Investigaciones Sociales 24: 67-88. Lima: Instituto de Investigaciones Histórico Sociales, UNMSM.

ESCALANTE, Carmen

2011 Proyecto Apu Ausangate. Modelo Características Socio - Culturales para un ACR. Cusco.

ESCOBAR, G.; Richard SCHAEDEL y NÚÑEZ DEL PRADO

1967 Organización social y cultural del sur del Perú. México: Instituto Indigenista Interamericano. 250 p.

ESPINOZA, Héctor

2004 «El joven Akanaku y las hijas del Apu Auzangate».

ESPINOZA, Waldemar

1973 «Colonias de mitmas múltiples en Abancay, siglos 15 y 16». Revista del Museo Nacional 39: 225-299, Lima.

ESTEVA, C.

1970 «Medicina tradicional, curanderismo y brujería en Chinchero». En: Anuario de Estudios Americanos, XXVI Tomo I.

FLORES OCHOA, J.

1976 «Organización social y complementariedad económica en los Andes centrales». En: XLII Congreso Internacional de Americanistas. París.

FRAZER, J.G.

1965 La rama dorada. Magia y religión. México: Fondo de Cultura Económica (FCE).

GARCILASO DE LA VEGA, Inca

1976 [1609] Comentarios Reales de los Incas. Copia digitalizada 1609, Tomo I. [1609]. Capitulo XVII: 26. Caracas: Biblioteca Ayacucho.

GODELIER, Maurice

1976 Antropología y Biología. Barcelona: Anagrama.

GOLTE, Jürgen

1980 La racionalidad de la organización andina. Lima: IEP. 
HARRIS, M.

1973 Raza y trabajo en América. Buenos Aires: Ediciones Siglo Veinte.

HEREDIA, Daniel

1953 «Vilcabamba - Apurímac». En: Revista del Museo del Instituto Arqueológico 15. Cusco.

INGEMET

1999 Estudio Glaciológico de la cuenca del río Aobamba. Octubre de 1999 encargado por EGEMSA al INGEMET.

JIMÉNEZ DE LA ESPADA, Marcos

1965 Relaciones Geográficas de Indias-Perú. Edición y estudio preliminar de J.U. Martínez. Tomo II. Madrid: Grafico Yagues,

LAYME, Modesto

2004 Los Caminos del Inka en Mollepata. Folleto sin edición. 2004

LEVILLIER, Roberto

1940 Don Francisco de Toledo, supremo organizador del Perú: su vida, su obra (1515-1582). Tomo II: sus informaciones sobre los Incas (1570-1572). 516 p. Buenos Aires: Espasa Calpe.

MASON, J.A.

1969 Las antiguas culturas del Perú. México: FCE.

METRAUX, A.

1973 Religión y magias indígenas de América del Sur. Madrid: Aguilar.

MURRA, J.V.

1975 Formaciones económicas y políticas del mundo andino. Lima: IEP.

1978 La organización económica del estado Inca. Colección América nuestra. América antigua. º 11. México, $270 \mathrm{p}$.

MURÚA, Martín de

2004 [1590] Historia y Genealogía de los Reyes Incas del Perú. Compilado por J. Ossio. Madrid: Colección Particular Galván.

ORLOVE, B.S.

1977 «lntegration through production: the use of zonation in Sgnar». En: American Ethnologist 4(1): 84-101.

ORTIZ, Alejandro

1982 «Dualidad Religiosa. Afinidad Esencial de la Religiosidad Andina». Boletín de Lima.

POLO DE ONDEGARDO, Juan

1906 «Los errores y supersticiones de los indios sacados del trabajo y averiguaciones que hizo el licenciado Polo de Ondegardo». Revista Histórica I(7). Lima.

PROYECTO QHAPAQ ÑAN - CUSCO

2007 Declaratoria del camino Pre hispánico Mollepata. Abra Salkantay- Playa (Santa Teresa) 2007. Ministerio de Cultura, Cusco.

QUISPE, Virginia

2007 Proyecto de Investigación Arqueológica e Histórico del Sistema Vial Andino del Chinchaysuyu. Qhapaq Ñan, Cusco.

REGAL, Alberto

2009 Los caminos del Inca en el antiguo Perú . 253 p. Lima: INC.

REINHARD, Johan

2002 Machupicchu. El centro sagrado. Instituto Machu Picchu. Cusco, Cimagraf.

ROWE, John

1979 «An account of the shrines of ancient Cuzco». Nawpa Pacha 17: 1-80. Berkeley.

SÁNCHEZ, N.

1978 Indios y tributos en el Alto Perú. Lima: IEP.

SANTA CRUZ PACHACUTI, Juan

1968 [1613] Juan Santa Cruz Pachakuti Yamki Salkamayhua. Relacion de antigüedades del reyno del Perú. Biblioteca de Autores Españoles. Tomo 209. Crónicas de Interés Indígenas. Mardid: Ediciones Atlas. 
SARMIENTO DE GAMBOA, Pedro

1965 [1572] Historia de los Incas. Segunda parte de la historia general llamada indica. Biblioteca de autores españoles. Mardid: Ediciones Atlas.

SQUIER, George

1974 Un viaje por tierras Incaicas. Crónica de una expedición arqueológica. 1863-1865. Prologo de Raúl Porras Barrenechea. Buenos Aires. UNMSM.

TAMAYO, José

1994 «Los Incas y el Cusco». En: Historia y Cultura del Perú:195-208. Lima: Universidad de Lima.

TERRADAS, I.

1971 «Allpa: Un modelo etnosemhntico». En: Ethnica 2: 205-222.

TSCHOPIK, H. Jr.

1968 Magia en Chucuito: los aymaras del Perú. México: Instituto Indigenista Interamericano.

VACA DE CASTRO, Cristóbal

1908 «Ordenanza de tambos 1543». En: Revista Histórica. Tomo III.

VALCÁRCEL, Luis

1980 Religión Incaica. Lima: Editorial Juan Mejía Baca.

VILLANUEVA, Horacio

1980 Cusco 1689. Documentos. Economía y Sociedad en el Sur Andino. Cusco: CBC.

WACHTEL, N.

1976 Los vencidos. Los indios del Perú frente a la conquista española (1530- 1570). Madrid: Alianza Universidad.

WOLF, E.

1971 Los campesinos. Barcelona: Labor.

ZAVALA, S.

1978 «El servicio personal de los indios en el Perú (extractos del siglo XVI)», En: México, El Colegio de México. 1979. El servicio personal de los indios en el Perú (extractos Del siglo XVI 4, 11. México, El Colegio de México.

\section{FONDOS CONSULTADOS. ARCHIVOS HISTÓRICO Y ARZOBISPAL DEL CUSCO}

- ARC: Protocolos Notariales. Testimonios Compulsas. Legajo 1. XVI-XVII. 1646. Expediente de composición de tierras en Mollepata que se hace a favor de doña Micaela de Villegas. Sin foliar.

- ARC: Corregimiento. Causas Ordinarias. Leg. 12. 1647-1648. Cuad. 9. Fol. 11.

- Autos seguidos por Fray Pedro de Albendiri, procurador del convento de San Agustín para que se le entregue los dos indios señalados por el Virrey Velasco para el Tambo de Marcaguasi.

- ARC: Corregimiento Causas Ordinarias. Leg. 25. Años: 1689-1690. Cuaderno: 6. Contiene Varios testimonios desde 1595. Folios: 38-52.

- ARC: Protocolos Notariales N 17. Año: 1687. Cristobal de Bustamante.

- AAC: Provincia de Abancay, 1603. Folios: 75-85.

- ARC: Libro de Cabildo. $N^{\circ}$ 9. Años: 1610-1612. Folios: 16v.

- ARC: Libro de Cabildo. N 15. Años: 1645-1649. Folios: 71v.

- ARC: Corregimientos. Año 1596-1604

- ARC: Libro de Cabildo No. 12. Años: 1623 - 1627. Con 213 folios

- ARC: Libros de Cabildo. N 5. 1564 - 1567. Folios: 15v. Documentos cortesía del historiador Donato Amado G.

- ARC: Libro de Cabildo $N^{\circ}$. 12. Años: 1623 - 1627. Con 213 folios.

- ARC: Fondo Cabildos de Cusco. Cuadernos 12, 14. Años 1570- 1620. Fol 34, 78. 